
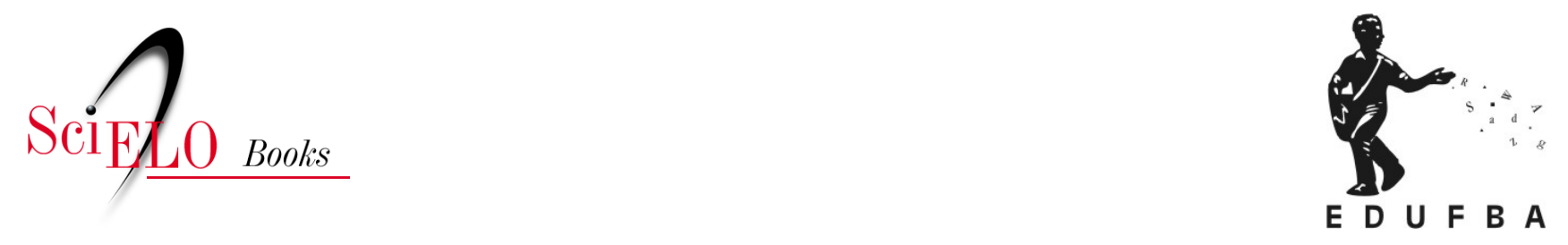

\title{
Trabalho Infantil Doméstico trabalho ou dever perante a família?
}

\author{
Danila Gentil Rodriguez Cal
}

\section{SciELO Books / SciELO Livros / SciELO Libros}

CAL, D.G.R. Trabalho Infantil Doméstico: trabalho ou dever perante a família? In: Comunicação e trabalho infantil doméstico: política, poder, resistências [online]. Salvador: EDUFBA, 2016, pp. 2947. ISBN: 978-85-232-1870-6. https://doi.org/10.7476/9788523218706.0004.

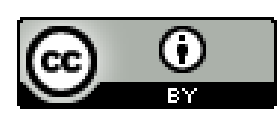

All the contents of this work, except where otherwise noted, is licensed under a Creative Commons Attribution $\underline{4.0 \text { International license. }}$

Todo o conteúdo deste trabalho, exceto quando houver ressalva, é publicado sob a licença $\underline{\text { Creative Commons }}$ Atribição 4.0. 


\section{Trabalho Infantil Doméstico: trabalho ou dever perante a família?}

Ao pé do casarão mal iluminado fatal foi pensares que ofereciam vida nova, pois ouviste os sinos. A família dormia ainda. Soubeste logo que havia menino, que havia menina, um doutor e sua mulher a quem devias servir, branca e alta mulher. [...] Mas ao ouvir a voz 'Ó pequena', desabalada era a tua carreira pelas escadas, era a hora de retirar o urinol de porcelana com a urina da branca senhora que ficou roxa um dia porque te pegou dizendo 'pêra lá que eu vou tirá o mijo da mulhé' e te trancou e quase te esmagou na porta para que consertasses a língua, Ó pequena! Terias que dizer 'fazer o meu serviço, cumprir minha obrigação’ aprendeste logo sem compreender. (MEDEIROS, 1990, p. 11-12)

Na literatura brasileira de expressão amazônica, são várias as referências a meninas que trabalham em casa de família como domésticas (JURANDIR, 1960; 
CECÍLIA, 2003, MEDEIROS, 1990) e à saída de pessoas ainda crianças de municípios longínquos para realizarem serviços domésticos em Belém, capital do Pará. O conto Velas. Por Quem?, da paraense Maria Lúcia Medeiros, ilustra as aflições e vivências de gerações e gerações de brasileiros - ou melhor, brasileiras - pouco consideradas quando se trata da história do nosso país.

A menina, cria da casa, agregada, vai crescendo à sombra dos patrões e a serviço deles. O conto relata a vida de uma garota que vive à mercê das "bulinações" dos patrões, pai e filho, e que é passada "como herança” à filha da patroa, quando esta morre. A menina é retratada como aquela que teve a vida roubada e que "aprendeu como cachorro de sítio a sair com o rabo entre as pernas repetindo 'sim, senhora”, ou é representada ainda como um "cachorro fiel”, sem condições de reação ou contestação: "fatal foi tua mansidão de bicho: o búfalo, a corça e o cão”. (MEDEIROS, 1990, p. 12)

Ao final do conto, fica claro que a doméstica, já senhora, está tendo sua "sorte" lida por uma quiromante que conclui: "não vejo mais - pesada hora - rastro sequer de fortuna, perdeu-se a do coração [...] fatal foi te roubarem a linha da vida”. (MEDEIROS, 1990, p. 13) A simplicidade e a beleza da escrita de Maria Lúcia Medeiros contrastam com a tristeza da vida da menina doméstica, captada pela sensibilidade da autora, como quem teve subtraídos os momentos da infância e da adolescência. Segundo Tupiassú (2005), essa prosa destaca "a representante do sem nenhum direito, desprovida de qualquer identidade social, um resto apenas, que sobrou da avassalagem dos antigos descimentos, ${ }^{1}$ hoje ainda um pesadelo em processo, não só lance da memória que dói”. (TUPIASSÚ, 2005, p. 312)

Apesar de retratar uma situação do início do século XX, Velas. Por Quem? permanece contemporâneo naquilo que revela do cotidiano de muitas famílias e de meninas no Pará e no Brasil. ${ }^{2}$ Parte significativa dos referenciais teóricos a respeito

1 Referência à chamada "indústria da descida ou descimentos", um tipo de expedição ao interior da floresta para escravizar indígenas. (LAMARÃO, 2008)

2 Segundo a Pesquisa Nacional por Amostra de Domicílios (PNAD), referente a 2011 e divulgada pelo Instituto Brasileiro de Geografia e Estatística (IBGE) em 2012, há no Brasil 257.691 crianças e adolescentes de 10 a 17 anos trabalhando como domésticas. No entanto, acreditamos que esse número é subestimado tanto pela natureza do tipo de pesquisa realizado (por amostragem) quanto pela dificuldade de caracterizar boa parte do serviço doméstico realizado por meninos e, sobretudo, meninas como "trabaIho". A respeito das críticas sobre os dados oficiais a respeito do TID, ver também Jacquemin, 2006. 
do Trabalho Infantil Doméstico (TID) considera crianças e adolescentes envolvidas nessa situação; sujeitos “invisíveis", levando em conta a precariedade das condições de existência (“um resto apenas”, como diria Tupiassú), a herança escravista do Brasil, que naturalizou situações de extrema exploração e fatores de gênero, já que, tradicionalmente, o serviço doméstico é considerado uma atividade feminina. (ALBERTO et al., 2009; ARAGÃO-LAGERGREN, 2003; BLAGBROUGH, 2008; HOYOS, 2000; INTERNATIONAL LABOUR ORGANIZATION, 2004; LAMARÃO, 2008; VIVARTA, 2003; HASAN; SALEEM, 2013)

A iniciação de meninas no trabalho doméstico ocorre como uma preparação para realização dessas tarefas em sua futura casa. Nesse sentido, as habilidades desenvolvidas na execução desse tipo de serviço não são reconhecidas como dignas de valor, já que existe certa naturalização dessas atividades como femininas em contraponto à ideia de que são competências adquiridas. (ALBERTO et al., 2009) Corrobora essa "invisibilidade" do problema a ambiguidade constituinte da relação entre patrões e a menina agregada, que oscila entre ser serviçal ou se sentir parte da família. (MOTTA-MAUÉS, 2012)

A partir da percepção desse contexto, discutiremos neste capítulo as definições teóricas acerca do TID e as relações de poder que atravessam essa prática. Acreditamos que a referência à "invisibilidade" do TID - e, por corolário, dos sujeitos envolvidos - diz do entendimento compartilhado por pesquisadores e organizações sociais de que o TID pode ser considerado uma forma de dominação.

De acordo com a Organização Internacional do Trabalho (OIT) (2011), os trabalhadores infantis domésticos têm maior probabilidade de ser explorados e são os mais difíceis de serem protegidos. O TID é definido por organizações internacionais e pelo governo brasileiro como uma das piores formas de trabalho infantil, isto é, como uma daquelas que não podem ser exercidas de modo algum por menores de 18 anos de idade. (ARAGÃO-LAGERGREN, 2003; BRASIL, 2008)

Diversos autores definem o TID como uma das atividades laborais mais opressivas e mais negligenciadas. (ARAGÃO-LAGERGREN, 2003; LAMARÃO, 2008; HASAN; SALEEM, 2013) "A criança na sua posição subordinada em relação ao adulto está ainda mais exposta a situações de exploração e de abuso como trabalhadoras domésticas”. (ARAGÃO-LAGERGREN, 2003, p. 100) Nesse caso, a gênese da sustentação de relações de poder estaria na infância e na construção de relações de gênero, de tal forma que meninas que trabalham como domésticas 
merecem atenção especial, tanto por serem meninas quanto por estarem na posição de empregadas. (ARAGÃO-LAGERGREN, 2003)³

A respeito da conceituação de TID, parte da literatura sobre o assunto aborda apenas as atividades exercidas na casa de terceiros. Assim, esse tipo de trabalho infantil é comumente definido como a realização de serviços domésticos por menores de 18 anos de idade na casa de outras pessoas que não são pertencem a seu núcleo familiar. (CENTRO DE DEFESA DA CRIANÇA E DO ADOLESCENTE, 2004; 2011; FUNDO DAS NAÇÕES UNIDAS PARA A INFÂNCIA, 1999) Trata-se, prioritariamente, de meninas que possuem longas jornadas de trabalho e em condições prejudiciais ao seu pleno desenvolvimento. (BLAGBROUGH, 2008; CENTRO DE DEFESA DA CRIANÇA E DO ADOLESCENTE, 2004, 2011)

De acordo com Flores-Oebanda (2006, p. 2, tradução nossa),

Trabalhadores infantis domésticos são pessoas com idade inferior a 18 anos que trabalham na casa de outras pessoas [...] realizando tarefas domésticas, cuidando de crianças, transmitindo recados, e, por vezes, ajudando o empregador a executar pequenos negócios em casa. Isto inclui crianças que são pagas pelo seu trabalho, assim como as que não são pagas ou recebem benefícios 'in-kind', como comida e abrigo.

Ainda que haja destaque para o trabalho feito na casa de terceiros, organizações como OIT e Fundo das Nações Unidas para a Infância (Unicef) reconhecem que, nos próprios lares onde moram com os pais, meninos e, sobretudo, meninas podem exercer atividades domésticas exaustivas, que exigem responsabilidade e que trazem prejuízos ao desenvolvimento da criança e do adolescente. Como afirma Sabóia, "o trabalho para a família pode exigir muito da criança, obrigando-a a trabalhar muitas horas e impedindo-a de frequentar a escola, dificultando o exercício pleno de seus direitos”. (SABÓIA, 2000, p. 5) No entanto, para as organizações sociais, enfrentar o trabalho executado pelas crianças nos lares das próprias famílias traz grandes desafios e, por essa razão, é compreensível a opção dessas entidades pelo combate ao trabalho realizado fora de casa. Se já é comple-

3 Ao estudar o TID na cidade da Guatemala, Aragão-Lagergren afirma que esse tipo de atividade é largamente aceito porque há uma cultura da servidão que justifica relações de power over dos grupos mais poderosos sobre os desprovidos de poder. (ARAGÃO-LAGERGREN, 2003) 
xa e opaca a configuração do TID exercido na casa de terceiros como atividade laboral (CAL, 2007), nas casas das suas famílias os sentidos atribuídos às atividades de crianças e adolescentes são mais distantes ainda da ideia de trabalho.

Há o esforço de diferenciar os afazeres domésticos realizados por crianças e adolescentes como atividade educativa em colaboração ao trabalho de um adulto e como TID propriamente, quando meninos e meninas são os únicos responsáveis por determinadas atividades do lar, por longo período, de modo que isso traga prejuízos ao tempo do lazer e ao direito à aprendizagem.

Os afazeres domésticos são atividades realizadas de forma a colaborar com a organização da casa e com o trabalho pelo qual um adulto é responsável. Por outro lado, o trabalho doméstico se refere a um "conjunto das tarefas de cuidar da casa, de pessoas ou animais, que podem ser realizadas para o próprio núcleo familiar ou para terceiros, sendo que, neste último caso, a remuneração pode ser feita em espécie ou em gêneros”. (ALBERTO et al, 2009, p. 61) É essa definição mais abrangente que utilizaremos como ponto de partida deste livro. Consideramos, portanto, que é possível que crianças e adolescentes executem trabalho doméstico no próprio núcleo familiar e que esse tipo de atividade envolve relações de poder, assim como quando o TID ocorre em casa de terceiros.

\section{ASPECTOS CULTURAIS E SOCIAIS DO TRABALHO INFANTIL DOMÉSTICO}

- Quando vestia uma roupa melhor era quando a patroa não queria mais ou a filha da patroa não queria mais 'manda cortar este vestido para Fulano'. Chegava época festiva época de Natal, não é? 'Manda cortar este vestido, não quero mais este vestido, manda cortar para Fulano, afirmou Acácia.

- É, era resto, concluiu Lulu.

- Era assim, concordou Acácia.

Grupo focal “Cidade de Emaús”.

A "invisibilidade" atribuída ao TID estaria relacionada principalmente a fatores históricos e culturais, tais como: a escravidão e o costume de trazer meninas de 
áreas rurais para estudar na capital e morar em casas de família; a concepção de que meninas devem assumir as tarefas domésticas como naturais da condição feminina e, portanto, como não trabalho e por ocorrer nas casas de família, distante, assim, dos olhares públicos. (ALBERTO et al., 2009; BLAGBROUGH, 2008; CAL, 2007; HOYOS, 2000; INTERNATIONAL LABOUR ORGANIZATION, 2004; LAMARÃO, 2008; LAMARÃO; MENEZES; FERREIRA, 2000; VIVARTA, 2003)

$\mathrm{Na}$ história do nosso país, é frequente a referência ao fato de meninas, filhas de escravos, serem levadas para as casas dos senhores para lhes servir de domésticas. (LAMARÃO, 2008; SILVA, 2009) Naquela época, "trabalhar era sinônimo de aprender a ser escravo", de aprender a obedecer e a servir ao senhor. (ALBERTO et al., 2009, p. 59)

No Pará, desde o período colonial, mulheres e meninas escravas já trabalhavam dentro das casas dos senhores cuidando dos filhos deles, realizando todo tipo de serviço doméstico e, não raro, sofrendo abusos sexuais por parte dos patrões. (LAMARÃO, 2008) Veríssimo (1970), ao contar parte da história da Amazônia, relata a escravização de filhas de índios para esse tipo de atividade. Essa situação reforçou o ciclo de pobreza e falta de qualificação, já que, após a escravidão, essas mulheres passaram a criadas ou domésticas e trocavam sua força de trabalho por comida ou baixas remunerações. (ALBERTO et al., 2009)

A esse respeito, Motta-Maués (2008) esclarece que, após a abolição da escravidão, as autoridades formaram em Belém um “corpo de trabalhadores", constituído, principalmente, por adolescentes e jovens trazidos de cidades do interior do Pará para realizar serviços públicos na capital. "E que, num desvio de finalidade, eram encaminhados às casas de autoridades do Estado para emprego nos serviços domésticos”. (MOTTA-MAUÉS, 2008, p. 158) De modo complementar, ao escrever sobre a memória da infância na Amazônia, Figueiredo (2007) destaca que, no início do século XX, “crias” ou irmãs "adotivas” serviam como acompanhantes de meninas da elite local, "revelando um costume muito arraigado não só na Amazônia como em outras partes do Brasil, por meio de uma eficiente 'circulação de menores' oriundos de famílias mais pobres”. (FIGUEIREDO, 2007, p. 340)

Segundo Lamarão (2008, p. 65), as feições atuais do TID ainda guardam resquícios daquele período histórico, sobretudo no que se refere ao recrutamento das meninas por um intermediário, ou ainda quando meninas eram entregues diretamente pelas próprias famílias a novos “protetores”. Também são resquí- 
cios daquela época o afastamento da convivência familiar e comunitária e os impactos que a mudança para a cidade gera na vida das crianças e adolescentes. Sobre a sociedade amazônica do início do século XX, Lamarão (2008) afirma que a socialização das meninas seguia padrões legitimados pela Igreja e pelo Estado, segundo os quais as ricas "eram disciplinadas para a maternidade e o cuidado do lar enquanto que as meninas pobres eram enviadas para o trabalho doméstico”, (LAMARÃO, 2008, p. 32) seja na condição de cria, seja na de agregadas das famílias.

Há uma distinção sutil entre adoção e criação, nesse caso. ${ }^{4}$ (FONSECA, 1995; MOTTA-MAUÉS, 2008) Quando se referem às crias, os responsáveis não utilizam os termos "filho/filha", mas sempre deixam claro que se trata de "menina que estou criando", "pessoa que peguei para criar”. Diante desse contexto, o conceito de "circulação de crianças" desenvolvido pela antropologia se mostra pertinente para analisarmos o TID. Ele consiste na "transferência temporária da responsabilidade sobre a criança de um adulto para o outro, com fins de seu cuidado e socialização”. (MOTTA-MAUÉS, 2012, p. 03) Por meio dessa noção, estudam-se os caminhos pelos quais crianças circulam entre diferentes lares, distintas famílias e as repercussões dessa movimentação para a vida de meninos e meninas e para os ambientes em que vivem. (FONSECA, 1995; MOTTA-MAUÉS, 2008, 2012)

Segundo Fonseca (1995), os caminhos que as crianças percorrem - ou são levadas a percorrer - têm relação com a concepção de infância espraiada pelo contexto social em que os pais estão inseridos. Nesse sentido, a classe média, em geral, parte da ideia de que a criança é um “adulto em formação” e que, portanto, merece atenção para o desenvolvimento emocional e intelectual. A criança, assim, “é inserida em uma estratégia familiar de ascensão socioeconômica a longo

4 Existem complexas relações entre a ideia de "adoção" e a de "criação", segundo autores como Cláudia Fonseca $(1995,2006,2012)$ e Maria Angélica Motta-Maués (2008; 2012). Devido ao escopo deste trabalho, restringir-nos-emos a apreender o que dessa complexidade repercute no TID e nas relações de poder que o sustentam. Assim, a concepção genérica apresentada por Fonseca se mostra adequada. Segundo essa autora, a adoção, tal como regulamentada nas leis brasileiras, significa um procedimento legal que estabelece uma nova relação de paternidade/maternidade em que há o "apagamento" da família de nascimento e o estabelecimento de uma igualdade formal entre a criança adotada e os filhos biológicos de quem a adota. Por outro lado, a "criação" refere-se a uma prática de circulação informal de crianças e implica, por vezes, um dever moral da criança em relação aqueles que a abrigaram, por exemplo, cuidar deles na velhice. Argumentamos que essa última guarda uma estreita relação com o TID. (FONSECA, 2006; 2012) 
termo”. (FONSECA, 1995, p. 30) Nas classes baixas, o entendimento prioritário é o da criança "como adulto incompetente". O trabalho dos pais ou responsáveis, desse modo, é “assegurar que certas necessidades 'objetivas' sejam atendidas”. (FONSECA, 1995, p. 31)

O TID se apresentaria, então, como uma possibilidade concreta de frequentar uma família com melhores condições socioeconômicas - ainda que, por vezes, apenas ligeiramente melhores do que suas famílias de origem - e de suprir "necessidades" imediatas relacionadas à sobrevivência, mas também à aquisição de bens de consumo. Na nova família, a posição subalterna da menina criada ou agregada em relação aos patrões e às outras crianças da casa é evidente e, geralmente, não questionada. (CARNEIRO; ROCHA, 2009; FONSECA, 1995; LAMARÃO, 2008)

Para Fonseca (1995), embora essa menina, não raras vezes, receba o tratamento de "filha de criação", não haveria ambiguidade na relação familiar porque os patrões quase nunca são chamados de pais e sim de "senhor fulano de tal" ou "Seu/Dona”. Entretanto, outros autores (CAL, 2007; LAMARÃO; MENEZES; FERREIRA, 2000; MOTTA-MAUÉS, 2012) afirmam que a ambiguidade dessa relação consiste em ora fazer parte da família - sobretudo, como uma relação entre madrinha/afilhada - e ora ser a empregada da casa ou a babá. A condição se torna clara em situações típicas, como quando, por exemplo, “ser da família” justifica o não pagamento de salário ou o pagamento de uma quantia mínima, enquanto que o "não ser da família” fica evidente nos momentos de lazer nos quais, normalmente, a menina doméstica fica responsável pela arrumação/organização dos itens do passeio, ou por cuidar das crianças ou ainda por carregar as bagagens, enquanto os demais membros da família têm como única função aproveitar a programação.

Motta-Maués (2008), por sua vez, aponta um traço de gênero que marca uma diferença forte entre crias meninas e meninos. Segundo a autora, quando se tratam de meninas, estas são criadas com a obrigação "quase natural” de executar serviços domésticos nos lares em que vivem e ainda continuam servindo a mesma família por várias gerações. Aos meninos, todavia, é reservado outro tipo de postura e comportamento. Eles são criados para buscar a vida fora de

5 Motta-Maués ressalta que a prática de circulação de crianças não é específica das classes populares. Nas mais abastadas, por exemplo, a circulação de crianças é frequente para a realização de cursos (línguas, reforço escolar) e atividades físicas, o que faz com que tenham uma "vida agendada", além da circulação entre casa da mãe, casa do pai, no caso de famílias separadas. (MOTTA-MAUÉS, 2012) 
casa e como agregados temporários daquela família. A principal ocorrência é de meninas na situação de "cria” ou de "filha de criação". (MOTTA-MAUÉS, 2008) Segundo a autora, "é justamente seu estatuto localizado, esdruxulamente, entre essas duas categorias ['cria' e 'filha de criação'], que dá à 'cria' um perfil e uma posição particulares na já longa história de sua presença nos lares da Amazônia”. (MOTTA-MAUÉS, 2008, p. 168)

Nem todas as trabalhadoras infantis domésticas são "crias" no sentido desenvolvido por Motta-Maués (2008, 2012), no entanto, essa é uma das faces mais antigas a respeito da complexa relação entre famílias empregadoras e meninas domésticas. De acordo com Marcílio (2006), que desenvolveu uma extensa pesquisa histórica sobre crianças abandonadas no Brasil (1726-1950), “a prática de criar filhos alheios sempre, e em todos os tempos, foi amplamente difundida e aceita no Brasil. São inclusive raras as famílias brasileiras que, mesmo antes de existir o estatuto da adoção, não possuíam um filho de criação em seu seio". (MARCÍLIO, 2006, p. 70) Ser "filha de criação" implica um dever moral perante àquela família, cuja generosidade de "pegar para criar” filhos dos outros é sempre ressaltada. Além disso, qualquer comportamento da "cria" considerado inadequado por parte dessa família é enquadrado como uma forma de ingratidão. (FONSECA, 1995; LAMARÃO, 2008; MOTTA-MAUÉS, 2008)

Em relação às meninas, há a expectativa por parte dos empregadores de que a condição de servidão se perpetue. (MOTTA-MAUÉS, 2008) Encontramos esse tipo de manifestação em nossa pesquisa de mestrado, quando entrevistamos patroas a respeito do TID. (CAL, 2007) Empregadoras de classes média e alta relataram que, por vezes, desejam que essas meninas não obtenham sucesso na vida para não modificarem sua condição na casa da patroa. A seguir, reproduzimos um trecho do grupo focal realizado na casa de uma das entrevistas no bairro Umarizal, de Belém, em 7 de agosto de 2006:

Virgínia: Eu posso falar uma coisa que eu acho que passa com a gente, quando você pega uma boa menina [...] você torce pra que ela não entre numa universidade, às vezes, hoje em dia.

Eva: Por quê?

Virgínia: Porque a maioria, você vai perder isso.

Eva: Ah, sim, mas aí tá errado, né.

Dina: Claro que tá errado, você tem que ajudar ela a crescer na vida. 
Virgínia: Tá errado, mas como há exceções, quando você quer...

Eva: Aproveitar porque ela é uma boa empregada...

$[\ldots[$

Virgínia: Aí quando vai chega na faculdade [...] a gente é boazinha trata como pessoa da família, mas a gente inconscientemente com medo de perder... [...] a gente tolhe às vezes um passo maior daquela pessoa de ser mais alguma coisa.

Dina: Por egoísmo nosso.

(As outras participantes concordam).

Eva: Até inconscientemente.

Dina: Mas a gente começa a travar.

Virgínia: Não é nem prejudicar você pára, estanca, você... [...]

(CAL, 2007, p. 129-130, grifo nosso)

As patroas admitem que impedir o crescimento profissional da menina não é correto, no entanto, reconhecem que não desejam que "boas empregadas" gozem de realizações pessoal e profissional porque têm medo de perder a criada, o que justificaria restringir as possibilidades "daquela pessoa de ser mais alguma coisa".

Nesse mesmo grupo focal, a participante Eva relatou ainda que a mãe tinha o costume de batizar meninas do interior para que pudesse trazê-las para criar na capital. Trazidas ainda crianças, as meninas iam se acostumando àquela família, eram "colocadas do jeito da gente", nas palavras da entrevistada, e iam passando de geração em geração até que não pudessem mais servi-los ou que morressem. Situação semelhante é discutida por Motta-Maués (2008) quando relata o modo contrariado pelo qual uma família "empregadora” recebeu a notícia da vontade de casamento da "cria", já aos 50 anos de idade, depois de cuidar de duas gerações de crianças da família empregadora.

Nas situações apresentadas (em relação à faculdade e ao casamento), é como se buscar caminhos próprios fosse uma afronta à generosidade das famílias que as criaram e em relação às quais estas sempre se encontram como devedoras. Desse modo, "pegar uma criança para criar" implica não apenas a responsabilidade com ela, mas essencialmente a responsabilidade da "cria" para com a família que a recebeu. Várias "filhas de criação" permanecem a vida inteira em torno das famílias que as criaram num "como se" quase permanente. "Como se" fossem parte da família, "como se” pudessem tirar férias, “como se” pudessem 
namorar os mesmos tipos de garotos que as filhas da patroa, "como se" tivessem as mesmas condições de vida e consumo que as famílias às quais servem.

Nesse sentido, a condição de agregada, ainda que livre em contraposição àquela do escravo, é sustentada em uma enorme dependência da menina em relação aos patrões, "uma vez que tudo que deseja e passa a desejar não pertence a si, mas sim a essa família, que, como constante ameaça, pode lhe dar e tirar de acordo com as circunstâncias”. (CARNEIRO; ROCHA, 2009, p. 134-135)

Entrelaçada a esses fatores históricos e culturais, está, ainda, a falta de percepção do trabalho doméstico como um trabalho de fato. Sendo uma atividade executada preponderantemente por meninas, estaria ligada a certa obrigação feminina de cuidar dos afazeres da casa. Essa percepção é compartilhada, por vezes, pelas próprias adolescentes trabalhadoras que se consideram "desocupadas”. (HOYOS, 2000) A inserção no trabalho doméstico ocorre, então, como se fosse imposição de gênero e um tipo de serviço mais próximo da realidade das meninas envolvidas. (LAMARÃO; MENEZES; FERREIRA, 2000) Outro modo pelo qual o TID não é visto como trabalho se baseia na sua realização como forma de aprendizagem das tarefas de reprodução e também como uma contribuição à rotina da casa, ainda que exija esforço e tenha uma jornada longa. (ALBERTO et al., 2009, p. 59)

Após a discussão desses diversos fatores que sustentariam a "invisibilidade" atribuída ao TID, percebemos com mais dúvidas essa perspectiva. Não somente porque o TID não está restrito às casas, já que as extrapola e aparece em praças públicas, nos supermercados ou em consultório de pediatras, com meninas domésticas acompanhando patroas e crianças, mas, principalmente, por supor que os fatores que denominamos como de "invisibilidade" do TID são, na verdade, produto e consequência de relações de poder que os alimentam e são alimentadas por eles. Ao mesmo tempo em que é sustentada por relações de poder principalmente de dominação -, a referência à ideia de "invisibilidade" do TID apela para a dificuldade de tematização pública dessa prática como um problema político, na medida em que questiona a aceitação social do TID e convoca os cidadãos a o "enxergarem" como algo sobre o que a sociedade deve discutir.

Na próxima seção, abordaremos com maior aprofundamento uma das relações de poder mais frequentemente atribuída ao TID: power over, em cujo cerne está a dominação. 


\section{TRABALHO INFANTIL DOMÉSTICO COMO DOMINAÇÃO?}

- Desde a idade de dez, onze anos que eu trabalho em casa de família. Eu não recebia pagamento, o que eles me davam era sapatinho, roupa, o que eu precisasse eles me davam. E hoje em dia eu já luto com um bocado de dificuldade porque eu já estou com 51 anos e ninguém mais quer me dar trabalho. Eu estou trabalhando como diarista, mas não é uma assim uma coisa certa, não é? Porque, de uma hora para outra, eles podem me despedir e colocar outra pessoa, mais nova do que eu no caso.

Nete, participante do Grupo focal "Sindicato I".

Os pesquisadores preocupados com o TID concordam que essa atividade expõe crianças e adolescentes a situações de risco, a humilhações e a maus-tratos, como resultados das condições físicas e emocionais nas quais se desenvolve. (CARNEIRO; ROCHA, 2009; LAMARÃO; MENEZES; FERREIRA, 2000) Para Lamarão (2008), por exemplo, a dominação simbólica é uma das principais características do TID, o que faz com que ele seja travestido na forma de um benefício mútuo para patroas e meninas empregadas, quando, na verdade, trata-se de um poder latente, que pressupõe a internalização dos valores dominantes pelo dominado. A autora conclui que:

[...] essa dominação ultrapassa as fronteiras de uma relação econômica, que é potencializada e oculta ao mesmo tempo por ser mais que um trabalho, realizado em um contexto de dominação, de opressão, de mando, porque envolve um processo instituidor de condutas submissas e subalternas que se tornaram habitus e se expressaram como estigma. (LAMARÃO, 2008, p. 154)

A dominação ativa no TID, portanto, materializa-se no modo mesmo pelo qual as meninas trabalhadoras se posicionam e se apresentam na realização das atividades domésticas e na relação com a família empregadora. Como se elas carregassem "inscrito em seu[s] corpo [s] o legado de classe". (CARNEIRO; ROCHA, 2009, p. 140) "Classe” é entendida por esses autores tal como proposto por Souza (2009), e diz respeito, nesse caso, à reprodução e assimilação afetiva de consensos não admitidos que naturalizam a divisão da sociedade em gente e 
subgente, entre classes média e alta e a ralé, como o autor se refere "provocativamente" a toda uma classe de "despossuídos", na qual ele enquadra a empregada doméstica, o que discutiremos mais detalhadamente no terceiro capítulo.

Segundo Blagbrough e Glynn (1999), o TID ocorre principalmente em sociedades nas quais é comum contratar empregados domésticos de modo geral e onde é aceito que um grupo étnico - ou classe, para usar os termos de Souza - sirva a outro. O Brasil é um desses países em que a desigualdade social é tão profunda que estimula uma percepção ampla de que uns sujeitos devem ser servidos por outros, ideia que nos parece bastante viva, principalmente no modo como os nortistas pensam e situam o lugar social dos empregados domésticos. Na coletânea História das Crianças no Brasil (PRIORI, 2007), há relatos de diversos pesquisadores sobre a servidão e o trabalho das crianças. Segundo Priori, "A estratificação da sociedade, a velha divisão dos tempos da escravidão entre os que possuem e os que nada têm, só fez agravar a situação de nossos pequenos”. (PRIORI, 2007, p. 14)

Nesse sentido, as afirmações de Alberto e outros (2009) em relação ao trabalho infantil corroboram ainda as considerações de Souza sobre a manutenção e reprodução da desigualdade em nosso país. Para esses autores, há modos sutis de dominação, como "a domesticação do corpo e da mente [de meninos e meninas] para o trabalho, além da introjeção do trabalho como elemento formador ou, ainda, como antídoto para a marginalidade”. (ALBERTO et al, 2009, p. 60, grifo nosso) De acordo com Rizzini (2007), as famílias dessas crianças e adolescentes entendem o trabalho como um mecanismo disciplinador. Assim, "a 'escola do trabalho' é percebida como a verdadeira 'escola da vida' - a criança é socializada desde cedo para ocupar o seu lugar em uma sociedade extremamente estratificada, onde lhe são reservadas as funções mais subalternas”. (RIZZINI, 2007, p. 389)

O próprio contexto onde o TID se realiza, o lar, é marcado por relações de poder, que estabelecem quem pode falar e ordenar e quem deve obedecer. Como ressalta Max Weber (1991b), tipicamente, o espaço doméstico reproduz relações tradicionais de domínio, a partir de uma fidelidade inculcada pela tradição e pelo hábito. Na literatura feminista, o lar é um dos lugares onde as mulheres - e, podemos acrescentar, as crianças - podem ser mais assujeitadas e oprimidas. (OKIN, 2008) Em relação ao TID, a dominação ocorre, sobretudo, entre mulheres: a que contrata ou "cria" e a empregada ou "criada". Apesar de os membros da família do sexo masculino terem a possibilidade de exercer poder sobre a me- 
nina trabalhadora doméstica, quem é tradicionalmente colocada como responsável por orientar, ensinar os modos de fazer o serviço doméstico de preferência daquela família e a quem é cobrada a fatura caso a menina não cumpra como deveria suas atividades é a patroa.

Ao estudar as concepções de poder mobilizadas pelas teorias feministas, Allen critica noções que consideram o exercício do poder pelas mulheres um uso benevolente, como se as mulheres fossem sempre virtuosas ou como se fizessem exercício do poder apenas de modo "maternal": "Nós não somos incapazes ou relutantes em usar nosso poder para ferir os outros simplesmente porque somos mulheres; muitas mulheres têm acesso ao poder sobre outras mulheres em virtude de sua raça, classe e/ou orientação sexual”. (ALLEN, 1998, p. 31, tradução nossa) Como discutimos, o TID é uma prática que pode favorecer esse tipo de relação. Ainda que seja vitimizada pelo marido e, por vezes, pelos filhos, a mulher dona da casa exerce, em geral, poder sobre a menina doméstica e sobre capacidade de decisão a respeito de escolhas da menina, como tratamos anteriormente no caso das patroas que admitem não querer o sucesso profissional em outras áreas das boas empregadas.

Uma das faces mais claras dessa situação de dominação é quando trabalhadoras infantis domésticas são humilhadas, maltratadas, castigadas e até abusadas sexualmente pelos patrões ou filhos deles. Ainda que as meninas relatem o abuso às patroas, estas geralmente não acreditam ou então atribuem a culpa às domésticas "que provocaram os desejos do patrão" por meio do uso de roupas provocantes ou insinuações. (LAMARÃO; MENEZES; FERREIRA, 2000) Acerca desse assunto, em outro trabalho (MAIA; CAL, 2012) relatamos o depoimento de uma ex-trabalhadora infantil doméstica que, ao informar à patroa sobre a tentativa de abuso sexual por parte do filho desta, a dona da casa reagiu, dizendo que o menino era patrão dela e, portanto, tinha o direito de fazer o que bem quisesse.

Essas vivências podem repercutir na imagem que as meninas têm de si, como alertam Alberto e outros (2009, p. 59):

O trabalho infantil doméstico, em particular pela humilhação, pela baixa autoestima e pela descaracterização como trabalhador, poderá promover o embotamento afetivo. Da imagem de si emergirá ou não uma estima de si, como o amor próprio, influenciada pela maneira de imaginar-se como será visto pelos outros 
Desse modo, o TID pode acarretar formas de desrespeito que geram perda da autoconfiança, do autorrespeito e o reforço a hierarquias sociais negativamente valorativas em relação aos sujeitos que o exercem. Formas tornadas cotidianas de agressão e rebaixamento moral por meio da demonstração recorrente do lugar que cabe a essas meninas nas famílias em que vivem/trabalham ou ainda na sociedade de modo geral - como, por exemplo, em relação ao tipo de roupa que a adolescente deve vestir para acompanhar a criança de quem cuida ao shopping ou ao supermercado, ou ainda o modo como deve, a adolescente trabalhadora, se comportar nessas ocasiões - podem repercutir na maneira pela qual essas meninas se consideram ou não dignas de respeito.

Nesse sentido, a distinção analítica que Honneth (2003) faz em relação ao desrespeito, parece-nos pertinente para lançar luz acerca do TID. Voltaremos a essa discussão no terceiro capítulo. Por ora, interessa-nos pontuar como essas categorias de desrespeito podem contribuir para problematizamos o TID. Honneth (2003) aborda três principais tipos de desrespeito: (a) Desrespeito como maustratos e violação; (b) desrespeito como privação de direitos; (c) desrespeito como degradação e ofensa.

Maus-tratos a trabalhadoras infantis domésticas são largamente retratados na maior parte das pesquisas sobre o tema. (FLORES-OEBANDA, 2006; FUNDO DAS NAÇÕES UNIDAS PARA A INFÂNCIA, 1999; INTERNATIONAL LABOUR ORGANIZATION, 2004, 2013; LAMARÃO, 2008; LAMARÃO; MENEZES; FERREIRA, 2000) A humilhação é a sua forma mais habitual e decorre, sobremaneira, do modo pelo qual a trabalhadora infantil é vista naquela família, isto é, como alguém que deve obediência inquestionável aos patrões, como quem merece constante correção com a finalidade de se ajustar aos comportamentos que a família empregadora considera adequados para uma menina criada ou trabalhadora doméstica. (MOTA-MAUÉS, 2008) Como afirmam Hasan e Salleem, "trabalhadores infantis domésticos estão também sobre o risco do abuso, da violência e da crueldade rotineira. Eles também sofrem abuso pelas mãos dos filhos dos patrões e de seus pais”. (HASAN; SALEEM, 2013, p. 43, tradução nossa) Embora estes últimos autores tenham como foco a análise da situação do TID na Ásia, essas reflexões coadunam-se às pesquisas realizadas no Brasil em relação aos maus-tratos relacionados à situação de TID. (LAMARÃO, 2008)

Sob o ponto de vista dos direitos, estudiosos e organizações sociais afirmam que o exercício do TID acaba por subtrair vários direitos conquistados 
por crianças e adolescentes, principalmente aqueles relacionados à educação e à aprendizagem, à convivência com a família e a comunidade, à proteção contra maus-tratos, aos abusos físicos e à violência sexual, entre outros. (FLORESOEBANDA, 2006; FUNDO DAS NAÇÕES UNIDAS PARA A INFÂNCIA, 1999; INTERNATIONAL LABOUR ORGANIZATION, 2004) Segundo a OIT, os oito principais riscos ocasionados pelo TID são: longas horas de trabalho, trabalho físico pesado, abuso físico ou emocional, abuso sexual, precárias condições de vida, salários baixos ou ausência de pagamento, falta de oportunidades educativas e falta de oportunidades para o desenvolvimento emocional e social. Isso porque "além do que a carga de trabalho, as exigências físicas e psíquicas fazem com que o TID exproprie as crianças e os adolescentes do tempo do ócio, próprio e necessário ao brincar e ao desenvolvimento”. (ALBERTO et al., 2009, p. 60)

Acerca do direito à educação, Alberto e outros (2011) afirmam que a defasagem escolar, ou seja, estar numa série atrasada em relação à idade, é recorrente entre as crianças e adolescentes trabalhadoras domésticas, em razão das longas jornadas de trabalho e do pouco tempo que elas dispõem para se dedicar aos estudos.

Relações de TID também podem resultar em degradação e rebaixamento moral. Nas hierarquias de prestígio predominantes em nossa sociedade, o trabalho doméstico ou reprodutivo - em contraposição ao economicamente produtivo -, de modo geral, é considerado uma atividade desvalorizada. (ALLEN, 1998; OKIN, 2008; YOUNG, 2007) De acordo com Souza (2009), essas hierarquias são percebidas a partir da análise do modo como sujeitos e grupos de certa sociedade se percebem e se julgam. Para esse autor, elas são histórica e socialmente construídas e ajudam a explicar o "DNA simbólico” de uma sociedade, segundo o qual certas virtudes ou características são condenadas ou estigmatizadas, enquanto outras são valorizadas.

Por outro lado, Carneiro e Rocha (2009) lembram que outro modo de ver essa situação seria considerar que há modos particulares e autênticos das pessoas da "ralé"6 viverem suas vidas que não seja situando-as na escala mais baixa dessa hierarquia valorativa. Porém, os autores afirmam que se trata de uma forma enganosa de enxergar a realidade, especialmente no caso das trabalhadoras domésticas. Ao analisar a história de uma doméstica chamada Leninha,

6 Referência que os autores fazem ao termo utilizado de modo provocativo por Souza (2009) para chamar atenção para esse grupo social. 
eles reconhecem a conquista de alguns avanços do ponto de vista dos direitos, entretanto, afirmam que há um silenciamento acadêmico e social em relação aos dramas e aflições aos quais essas mulheres são submetidas. Segundo Carneiro e Rocha (2009), esse silêncio repercute até mesmo entre as próprias envolvidas, que parecem "não articular com clareza e consequência a sua própria condição, pelo simples fato de que essa condição encerra uma realidade intragável [...]. Nenhum ser humano suportaria viver da verdade de tamanho desvalor social objetivo”. (CARNEIRO; ROCHA, 2009, p. 142)

No entanto, há outras possibilidades de resposta em relação a essa falta de clareza a respeito da própria situação por parte das trabalhadoras domésticas (principalmente, as infantis, nosso tema de estudo). Pode haver argumentos e formas de reconhecimento social que alicerçam condições de vida consideradas subalternas, como em relação ao TID (MAIA; CAL, 2014), ainda que eles contribuam para a construção de uma imagem de si em conformidade com a ordem dominante. (HONNETH, 2007) Para Honneth, trata-se do "reconhecimento ideológico", baseado num sistema de crenças que permite aos sujeitos envolvidos mobilizarem razões para justificar escolhas e posicionamentos ainda que essas decisões corroborem com a sustentação de mecanismos ideológicos. Dessa forma, o reconhecimento ideológico "garantiria a disposição motivacional para cumprir determinadas tarefas e deveres sem resistência”. (HONNETH, 2007, p. 336, tradução nossa) O reconhecimento, moralmente justificado, seria o contraponto quando as promessas são, de fato, cumpridas e abrem caminho para a autorrealização dos sujeitos.

O sistema de crenças que propicia a existência do reconhecimento ideológico possui três características específicas, conforme apontado por Rousiley Maia e Cal (2012, p. 4):

O sistema de crenças em questão deve: i) conceder uma expressão positiva ao valor das pessoas ou aos membros de um grupo, para que eles possam estabelecer uma auto-relação positiva; ii) ser 'crível' aos olhos daqueles a quem é endereçado, de modo a ser percebido como algo que realisticamente reforça os próprios sentimentos de autovalor e não restringe a própria autonomia; iii) proporcionar expressão a alguma nova conquista ou a um novo valor, de modo que os sujei- 
tos se sintam mais propensos à ganharem distinção, em comparação com o passado ou com situações anteriores.

Podemos relacionar cada uma dessas características ao TID. (MAIA, R.; CAL, 2012) Para várias meninas e mulheres envolvidas com essa prática, a inserção no TID se apresenta como uma oportunidade de morar com uma boa família, passear em lugares que normalmente não frequentam, viajar e estudar em escolas consideradas melhores (CAL, 2007; LAMARÃO; MENEZES; FERREIRA, 2000), além de ter acesso a bens de consumo que alimentam certo "status", como roupas e celulares, ainda que de segunda ou terceira mão. Essas "promessas" acerca do trabalho infantil doméstico são críveis, não somente porque há casos - poucos, é verdade - de meninas que conseguiram seguir nos estudos ou ter um bom casamento por meio do trabalho em casas de família, mas, principalmente, por parecer como a oportunidade concreta para muitas meninas de "obter sucesso na vida”. O exercício do TID pode estimular ainda a expressão de uma nova conquista materializada por meio de referências aos aprendizados sociais propiciados pelo contato com uma família de uma classe distinta da menina trabalhadora. (CARNEIRO; ROCHA, 2009; MAIA; CAL, 2014) Entretanto, as promessas que engendram o TID normalmente não são cumpridas e geram desrespeitos relacionados aos maus-tratos, propiciam a violação de direitos, a degradação e o estigma social.

A perspectiva de Honneth (2007) contribui para tornar mais complexa a resposta à pergunta sobre o porquê de sujeitos permanecerem ligados a uma relação de subordinação, recorrendo à ideia do reconhecimento ideológico e das bases racionais que o sustentam. No caso do TID, a perspectiva do reconhecimento ideológico possibilita o entendimento sobre as razões e os argumentos que meninas e mulheres diretamente envolvidas com essa prática mobilizam no sentido de justificarem esse tipo de atividade. (MAIA; CAL, 2014) Entretanto, entre o reconhecimento ideológico - a partir do qual relações de poder são suavizadas por meio de sistema de crenças que as justificam, o que prejudica a conversão do sofrimento ou do desrespeito em luta - e a luta política propriamente dita, parece-nos haver um espaço de resistência, de subversão e de construção de solidariedade que merece ser investigado. É nesse contexto que nossa pesquisa se insere. 
Como recurso necessário para explicação do fenômeno investigado e como pano de fundo fundamental deste livro, abordaremos no próximo capítulo o contexto da luta contra esse tipo de trabalho infantil, empreendida por organizações sociais e grupos de advocacy. 